\title{
Erratum to: The Placenta as the Mirror of the Foetus
}

\author{
Leonardo Resta, Roberta Rossi, and Ezio Fulcheri
}

\section{Erratum to:}

A. Malvasi et al. (eds.), Management and Therapy of Late Pregnancy Complications, DOI 10.1007/978-3-319-48732-8_1

The name of the author Roberta Rossi was incorrectly captured as Riccardo Rossi under the chapter title.

The updated online version of the original chapter can be found under DOI 10.1007/978-3-319-48732-8_1

L. Resta $(\bowtie)$

Department of Emergency and Organ Transplantation (DETO),

Section of Pathological Anatomy, University of Bari, Bari, Italy

University of Bari, Bari, Italy

e-mail: leonardo.resta@uniba.it

R. Rossi

University of Bari, Bari, Italy

E. Fulcheri

University of Genova, Genova, Italy 